\title{
ANALYSIS OF PRECAST SHEAR WALL CONNECTION- STATE OF THE ART REVIEW
}

\author{
Harsh R. Sanghvi ${ }^{1}$, Mazhar A. Dhankot ${ }^{2}$ \\ ${ }^{I}$ Research Scholar, Marwadi Education Foundation, Gujarat, India \\ ${ }^{2}$ Associate Professor, Civil Engineering Department, Marwadi Education Foundation, Gujarat, India
}

\begin{abstract}
The behavior of precast members in whole structure is different than cast in situ member due to their joints condition. So it is important to study the behavior of precast concrete member and its joints for whole structural configuration and loading condition. The precast concrete shear wall system is very important for construction due to economical advantages speed of construction. The connections between panels are extremely important since they affect both the speed of erection and the overall integrity of the structure. Comprehensive review reveals the significance of detailed analysis required for stress distribution form the precast member to the structural system to encounter the shear stresses generated during an earthquake event.
\end{abstract}

Keywords: Precast, shear wall, connection, cyclic loading

\section{INTRODUCTION}

The concept of precast (known as "prefabricated") construction includes those buildings where the majority of structural components are standardized and produced in plants in a location away from the building, and then transported to the site for assembly. These components are manufactured by industrial methods based on mass production in order to build a large number of buildings in a short time. Engineering precast concrete, like most other construction materials, requires consideration of various conditions other than the final in-service condition. The designer needs to consider manufacturing, handling, transportation, and erection of the product in addition to analysis and design for in-service loads. It is not uncommon for one of these temporary conditions to be the controlling factor in the design. Utilizing a Precast Concrete system offers many potential advantages over site casting of concrete. The production process for Precast Concrete is performed on ground level, which helps with safety throughout a project. There is a greater control of the quality of materials and workmanship in a precast plant rather than on a construction site.

\section{LITERATURE REVIEW}

The study of precast elements has gained a lot of popularity in recent times owing to the quality control and accuracy that can be achieved as compared to cast in situ members. Many researchers have worked to improve the performance of precast concrete members in case of its ability to resist the lateral force due to wind and earthquake. An attempt has been made in paper to summarize the study carried out by various authors and evaluate the requirement of further research in the area.
[1] Buildings that use shear walls as the lateral forceresisting system can be designed to provide a safe, serviceable, and economical solution for wind and earthquake resistance. Shear walls make up most common lateral force resisting systems in the precast, prestressed concrete industry. The design of connections is one of the most important considerations in the structural design of a precast concrete structure. The purpose of a connection is to transfer load, restrain movement, and provide stability. Within any one connection, there may be several load transfers; each one must be designed for adequate strength and ductility and be appropriately detailed. The detailing should take into account allowable tolerances, provide for a good fit between the selected materials and avoid interference between strand or reinforcing steel and the connection components, such as headed concrete anchors (also referred to as studs) or deformed bar anchors.

[2] This paper represent the behavior and capacity of different connection configuration used for precast concrete load bearing shear wall panels subjected to monotonic shear loading and cyclic loading condition. The static shear test results of dry packed multiple shear keys will enhance the maximum shear capacity by as much as 60 percent in comparison to the plain surface connections at same level of load. The ultimate shear resistance of the multiple shear key connection mainly depends on the level of load normal to the connection and bearing stresses and shear friction along the slip surfaces. The mode of failure for the cyclic shear specimens was due to sudden crushing and spalling of the dry pack grout, indicated by the significant reduction in the thickness of the grout.

[3] The research experimental program was designed to study the various limit states behavior and the shear capacity of the multiple shear keys used in horizontal connections. Failure of the plane surface connection was characterized by 
slip at the dry pack panel interface and the formation of a few cracks parallel to the load applied normal to the connection. This behavior indicated that the shear capacity of the plane surface connection mainly depended on the shear friction resistance at the dry pack panel interface.

As a results of the interlocking action of the dry pack shear keys, the maximum shear capacity of the multiple shear key connection was higher than that of the plain surface connection. The ultimate shear resistance of the multiple shear key connection was higher than that of the plain surface connection.

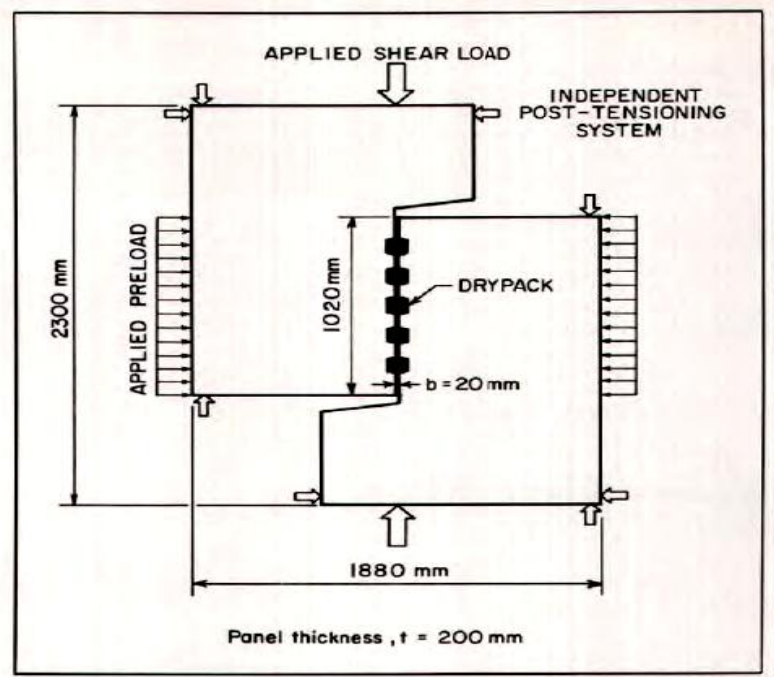

Fig-1 - Overall specimen dimensions with five keys.

[4] The study deals with the evaluation of precast wall connections subjected to in-plane lateral ground movement. For this purpose, 3D finite element model of precast walls and connection is developed using finite element model. By tracing the crack throughout the wall and connection, it can be mentioned that the crack propagations in the walls and connection mostly occurred at the bottom of the wall and along the interface simultaneously. The lateral in-plane loads show a few crack on the bond between the walls and connection.

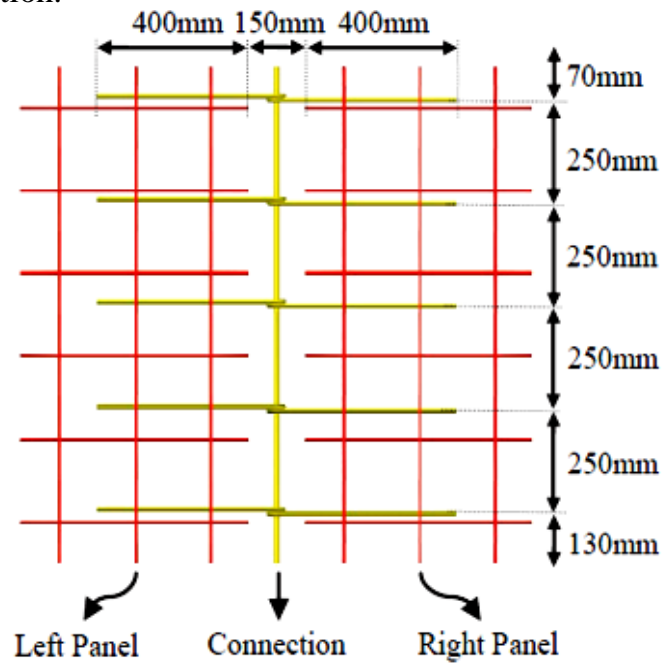

Fig 2 - Reinforcement Detailing
Based on the results it can assert that the common connection has also low efficiency in terms of capacity against lateral loading and consequently it can be claimed that the common connection role can be ignored in the lateral in-plane loading.

[5] A series of precast concrete wall panel specimens connected by dry-packed horizontal mortar joints was tested to assess their shear strength and failure mode under concentric and eccentric compression. Three different types of failure modes could be distinguished among the test specimens: 1) sliding failure; 2) grout failure. Sliding failure occurred by bond failure at the joint-panel interface. Grout failure occurs by diagonal cracks within the joint material.

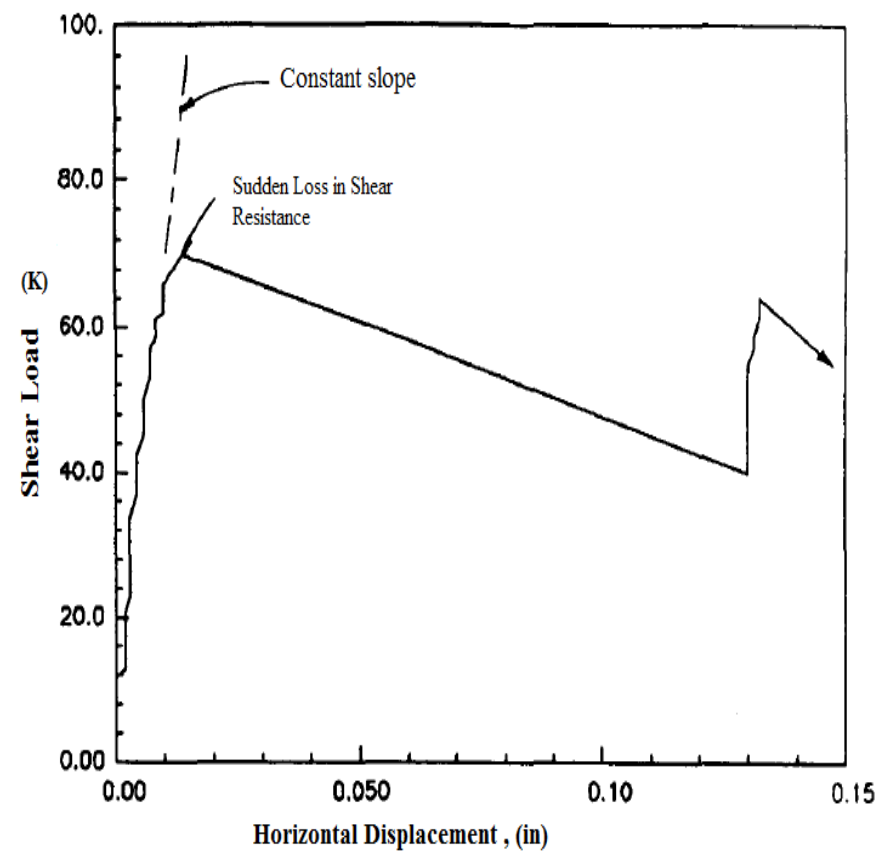

Fig 3 - Sliding failure of shear wall panel

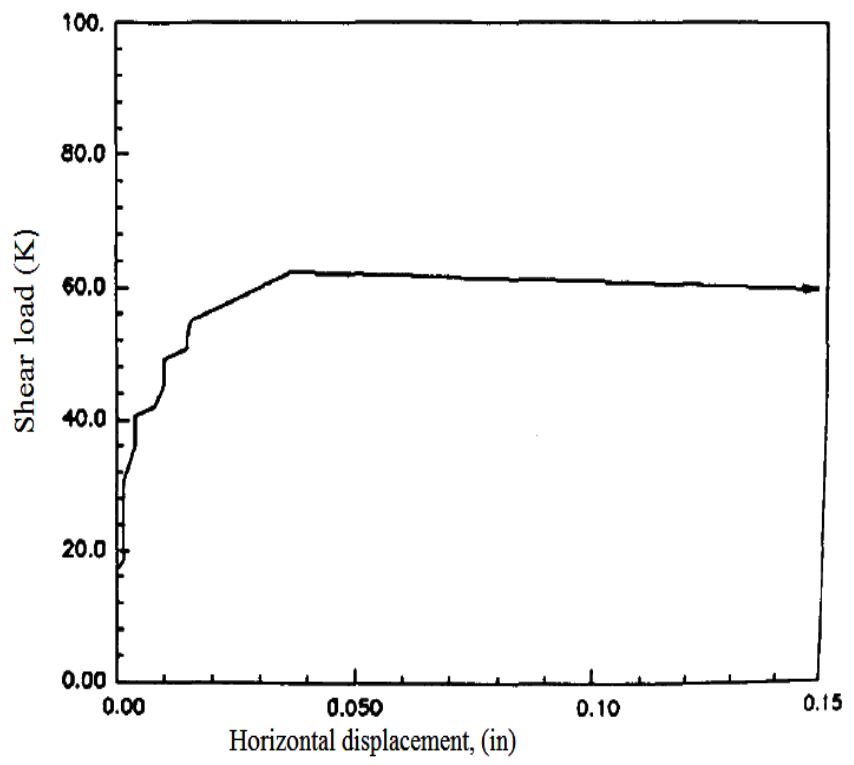

Fig 4 - Grout failure 
[6] A desirable feature of precast concrete walls is that they have large in-plane stiffness. Due to functional requirements, doors, windows or mechanical penetrations may be required in a shear wall. Sometimes, safety or security reasons mandate the presence of mod-erately large openings in the walls of parking structures. The consequence is that high stress concentrations arise in sections in which there are openings. Unfortunately, many two- and three dimensional. Computer programs do not or cannot account for these stress concentrations and related increased displacements. However, a general finite element model provides a powerful and accurate method for determining these stresses and displacements. The difference in deformed shape profiles increases with the size of the opening. With high speed desktop computers and advanced lateral analysis programs, such multiple computer runs would not be time consuming.

[7] An experimental program is undertaken to enhance the knowledge base regarding seismic design of precast concrete shear walls. The study is carried out for the behavior of connections between panels in slender precast shear walls. The use of grout splice sleeves can lead to tough connections which can be used with yielding reinforcing bars. Large deformation capacities can be ensured if suitable details are used to reduced compression damage of the concrete in the jambs and concentrated tensile strains in vertical reinforcement in the anchorage zone.Post tensioned connections appear to be well-suited for lateral load resistance as long as energy dissipation capacity is not essential.

[8] ETABS is used to analyze the shear wall structure of G+11 precast load bearing wall structure considering the gravity and lateral loads. The variation of shear force with storey level is non-linear. The difference shear force between zone-II and zone-V is $27.77 \%$. The maximum storey drift is increasing while increasing the storey level. Kevadkar and Kodag (2013) has carried out lateral analysis of R.C.C building and concluded that the lateral displacement of the building is reduced by $40 \%$ to $60 \%$ by the use of shear wall ${ }^{[10]}$.

[9] This paper presents a study on the connection between the exterior and interior precast concrete walls. The connection between the walls is called loop bars connection. Between the looping bars, one transverse bar is inserted as to ensure connectivity of all the looping bars. This connection produces a gap between the walls, which would then be filled with concrete to produce rigid connection. The main objective of these experimental studies is to determine behavior of loop bars connection under shear loading. From a visual observation, most concrete crushing and spalling was concentrated at the joint. Strut and tie model of loop joint used to model flow of forces in the connection. The crack showed zigzag pattern and it was developed as the force from one precast element to the other was being transferred by inclined compressive struts between overlapping loop bar. The connection shows a ductile behavior by producing a few line cracks and having a large deflection to give a warning before failure. This ductility is within the acceptable ductility of a structure.

[10] This study compares the lateral deformations and section forces of cantilevered shear walls in different building layouts by two different procedures. Walls that are 7 to $30 \mathrm{ft}$ (2. 13 to $9.14 \mathrm{~m}$ ) long are considered with two to six stories in height. The comparison shows that the simpler beam model (with shear deformations) yields displacement and force results that are very close to the more complex finite element approach with a fine mesh. Assumed for simplicity that rigid frames are not present in conjunction with shear walls and that the in-plane stiffness of floor diaphragms is extremely large compared to the stiffness of the walls. Therefore, it can be assumed that each floor diaphragm displaces in its plane as a rigid body. Linear elastic analysis was used in both the beam element and the finite element analysis procedures. The main tool in the beam element method was the LATERAL3 software. In the finite element analysis approach, the principal software was ANSYS, in one case, SAP-90 and the shell element in ANSYS were used as alternate methods for checking and comparison purposes. It is concluded that the beam model is an appropriate and accurate alternative to the more refined finite element method.

[11] The out-of-plane loading can be resisted either by the out-of-plane strength of the base connector or by the shear friction capacity of the grout bed.

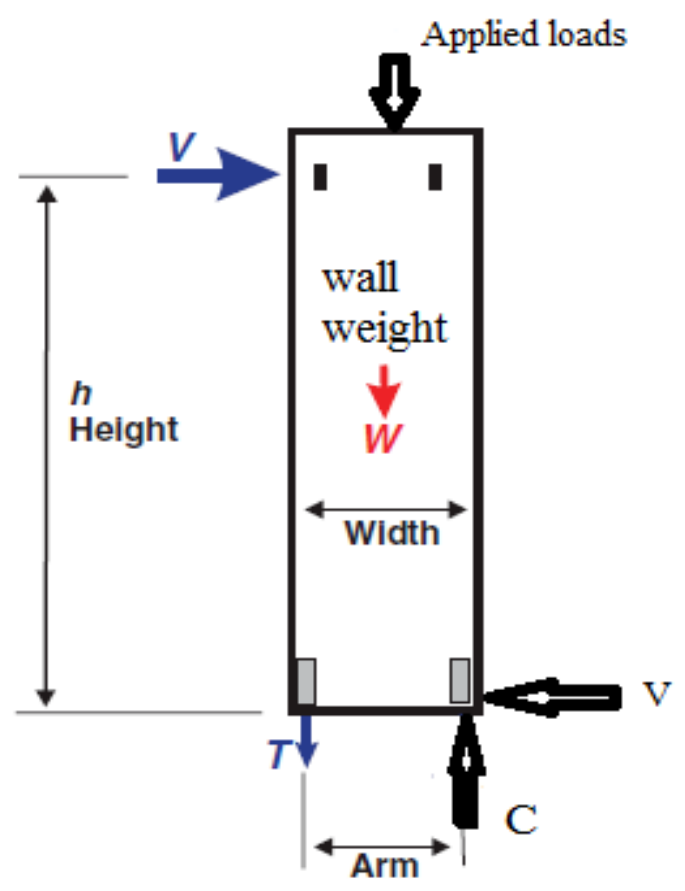

Fig 5 - Design requirements.

Prestressed concrete wall panels can easily be used to resist seismic loads if an alternate ductile mechanism is provided and the prestressing materials are not relied on for ductility. Walls with thin sections can form shear walls if the force transferred into the thin concrete section at the base is limited and brittle anchorage failure is avoided. 


\section{DISCUSSION}

Based on various researches, it is observed that base connections and connections at horizontal joints in precast columns and wall panels, including shear walls, must be designed to transfer all design forces and moments.

The presence of shear keys in the horizontal connection enhances the shear capacity in comparison to the plain surface connection. The difference in the shear key configuration had an insignificant effect on the behavior or capacity of connection. Increase in the level of load normal to the multiple shear key connection increase the shear capacity of the connection. The percentage increase in shear capacity is, however not equal to the percentage increase in load normal to the connection.

\section{CONCLUSION}

$>\quad$ Precast shear wall panels contains different type of side face joints and bottom face joints (Horizontal and vertical). The bottom face horizontal joints is important because of maximum stress generates at bottom face as the shear forces in the wall transfer to the structure through this junction.

$>\quad$ It is important to analyse different type of bottom face joint of precast shear wall panels.

$>$ Important to analysis the joint behaviour for in plane and out plane forces due to earthquake.

Different type of geometry for horizontal connection gives the different type of shear resistance for the same grout property.

The shear capacity of the multiple key connection is higher than the plain surface connection at same level of load.

\section{REFERENCES}

[1]. PCI DESIGN HANDBOOK-Precast and Prestressed Concrete-7TH EDITION.

[2]. S.H Rizkala, K.A.Soudki, J.West "Precast concrete shear wall connections. Used for medium and high-rise structure” PCI JOURNAL-March-April 1989.

[3]. Rizkalla S.H, Serrette R.L, Heuvel J.S, Emmanuel K. A" Multiple shear key connection for precast shear wall panels" PCI Journal March- April 1989.

[4]. Ramin V, Farzad H, Hafez T, Mohd S.J, and Abang Abdullah A.A "Evaluate Performance of Precast Concrete wall to wall Connection" 2013 2nd International Conference on Civil Engineering (ICCEN 2013).

[5]. Susan D. H, Alan C, Kurt H. G "Shear Strength of Horizontal Wall Panel Joints" PCI Journal-July 1990 Pg. No. 84

[6]. Seroj Mackertich, Alex Aswad "Lateral Deformations of Perforated Shear Walls for Low and Mid-Rise Buildings" PCI JOURNAL January-February 1997

[7]. R.A Magana, A.E Schultz "Design and behavior of connections in precast concrete shear walls." Eleventh world conference on earthquake engineering. Paper no 1738

[8]. A.Surekha, J.D.Chaitanya Kumar, E.Arunakanthi

"Analysis and connection designs of precast load bearing wall" IJRET: International Journal of Research in Engineering and Technology eISSN: 2319-1163 pISSN: 2321-7308

[9]. Kevadkar M.D and Kodag P.B (2013) "Lateral load analysis of R.C.C Building" International journal of modern Engineering research Vol.3. Issue.3 May-June 2013 PP1428-1434.

[10]. G. Gus Aswad, Basel Djazmati, Alex Aswad" Comparison of Shear Wall Deformations and Forces Using Two Approaches” PCI JOURNAL January-February 1999.

[11]. Can Bora, Michael G. Oliva, Suzanne Dow Nakaki, Roger Becker "Development of a Precast Concrete ShearWall System Requiring Special Code Acceptance" PCI JOURNAL-January-February 2007.

[12]. A.E Schultz, R.A Magana, M.k Tadros, X.Huo “ Experimental study of joint connection in precast concrete wall" Fifth U.S National conference on earthquake engineering vol. 2 July 1994

[13]. ACI-318 Building code requirements for Structural concrete and commentary.

[14]. ACI 533R-93 Guide for Precast Concrete Wall Panels.

\section{BIOGRAPHIES}

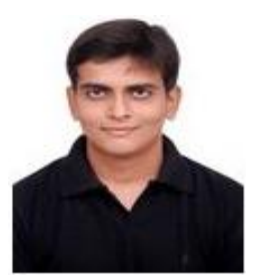

Harsh Rajeshhbhai Sanghvi was born in 1992 in Junagadh, Gujarat. He receives his Bachelor of Engineering degree in Civil Engineering from the RK College, Gujarat Technological University in 2013. At present he is Final year student of Master's degree in Structural engineering from Marwadi Education Foundation Group of Institutions, Gujarat Technological University.

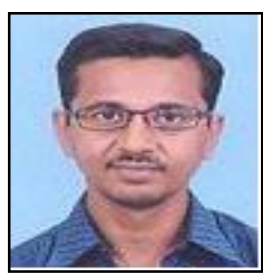

Prof. Mazhar A. Dhankot completed masters in CASAD from L. D. engineering college, Ahmedabad. Currently as an Associate Professor at Marwadi Education Foundations Group of Institute. He has an industrial and academic experience of more than 14 years. At present he is pursuing $\mathrm{PhD}$ in Base Isolation System. He has published about 10 papers in National and International conferences. 